\title{
Retrospective 8-Year Study on the Antibiotic Resistance of Uropathogens in Children Hospitalised for Urinary Tract Infection in the Emilia-Romagna Region, Italy
}

\author{
Susanna Esposito ${ }^{1, *}$, Giuseppe Maglietta ${ }^{2}$,, Margherita Di Costanzo ${ }^{3}{ }^{(}$, , Martina Ceccoli ${ }^{4}$, Gianluca Vergine ${ }^{5}$, \\ Claudio La Scola ${ }^{6}$, Cristina Malaventura ${ }^{7}$, Alice Falcioni ${ }^{8}$, Alessandra Iacono ${ }^{9}$, Antonella Crisafi ${ }^{10}{ }^{\circledR}$, \\ Lorenzo Iughetti ${ }^{4}{ }^{\mathbb{D}}$, Maria Luisa Conte ${ }^{5}$, Luca Pierantoni ${ }^{11}{ }^{\mathbb{D}}$, Claudia Gatti ${ }^{12}$, Caterina Caminiti ${ }^{2} \mathbb{1}$, \\ Giacomo Biasucci $^{3}{ }^{-1}$ and on behalf of the UTI-Ped-ER Study Group ${ }^{+}$
}

1 Pediatric Clinic, University Hospital, Department of Medicine and Surgery, University of Parma, 43126 Parma, Italy

2 Research and Innovation Unit, University Hospital, 43126 Parma, Italy; gmaglietta@ao.pr.it (G.M.); ccaminiti@ao.pr.it (C.C.)

3 Paediatrics and Neonatology Unit, Guglielmo da Saliceto Hospital, 29122 Piacenza, Italy; m.dicostanzo@ausl.pc.it (M.D.C.); g.biasucci@ausl.pc.it (G.B.)

check for updates

Citation: Esposito, S.; Maglietta, G.; Di Costanzo, M.; Ceccoli, M.; Vergine, G.; La Scola, C.;

Malaventura, C.; Falcioni, A.; Iacono, A.; Crisafi, A.; et al. Retrospective 8-Year Study on the Antibiotic Resistance of Uropathogens in Children Hospitalised for Urinary Tract Infection in the Emilia-Romagna Region, Italy. Antibiotics 2021, 10, 1207. https://doi.org/10.3390/ antibiotics 10101207

Academic Editors: Barbara Kot and Piotr Szweda

Received: 1 September 2021

Accepted: 1 October 2021

Published: 4 October 2021

Publisher's Note: MDPI stays neutral with regard to jurisdictional claims in published maps and institutional affiliations.

Copyright: (c) 2021 by the authors. Licensee MDPI, Basel, Switzerland. This article is an open access article distributed under the terms and conditions of the Creative Commons Attribution (CC BY) license (https:/ / creativecommons.org/licenses/by/ $4.0 /)$.
4 Paediatrics Unit, Department of Medical and Surgical Sciences of Mothers, Children and Adults, University of Modena and Reggio Emilia, 41125 Modena, Italy; martina.ceccoli90@gmail.com (M.C.); lorenzo.iughetti@unimore.it (L.I.)

5 Paediatrics Unit, Rimini Hospital, AUSL Romagna, 47921 Rimini, Italy; gianluca.vergine@auslromagna.it (G.V.); marialuisa.conte@auslromagna.it (M.L.C.)

6 Paediatric Clinic, IRCCS Azienda Ospedaliero-Universitaria di Bologna, 40138 Bologna, Italy; clasc1976@gmail.com

$7 \quad$ Paediatric Clinic, University of Ferrara, 44124 Ferrara, Italy; mlvcst@unife.it

8 Paediatric Unit, Forlì Hospital, AUSL Romagna, 47121 Forlì, Italy; alice.falcioni@auslromagna.it

9 Paediatrics and Neonatology Unit, Ravenna Hospital, AUSL Romagna, 48121 Ravenna, Italy; alessandra.iacono@auslromagna.it

10 Paediatrics Unit, Santa Maria Nuova Hospital, AUSL-IRCCS of Reggio Emilia, 42123 Reggio Emilia, Italy; antonella.crisafi@ausl.re.it

11 Paediatric Emergency Unit, IRCCS Azienda Ospedaliero-Universitaria di Bologna, 40138 Bologna, Italy; luca.pierantoni@aosp.bo.it

12 Paediatric Surgery, University Hospital, 43126 Parma, Italy; clgatti@ao.pr.it

* Correspondence: susannamariaroberta.esposito@unipr.it; Tel.: +39-0521-903524

+ Membership of the UTI-Ped-ER Study Group is provided in the Acknowledgments.

\begin{abstract}
The development and spread of antibiotic resistance is an increasingly important global public health problem, even in paediatric urinary tract infection (UTI). In light of the variability in the data, it is necessary to conduct surveillance studies to determine the prevalence of antibiotic resistance in specific geographical areas to optimize therapeutic management. In this observational, retrospective, multicentre study, the medical records of 1801 paediatric patients who were hospitalised for UTI between 1st January 2012, and 30 June 2020, in Emilia-Romagna, Italy, were analysed. Escherichia coli was the most frequently detected pathogen (75.6\%), followed by Klebsiella pneumoniae (6.9\%) and Pseudomonas aeruginosa (2.5\%). Overall, 840 cases (46.7\%) were due to antimicrobialresistant uropathogens: 83 (4.7\%) extended spectrum beta-lactamase (ESBL)-producing, 119 (6.7\%) multidrug resistant (MDR) and $4(0.2 \%)$ extensively drug resistant (XDR) bacteria. Empirical antibiotic therapy failed in 172 cases (9.6\%). Having ESBL or MDR/XDR uropathogens, a history of recurrent UTI, antibiotic therapy in the preceding 30 days, and empirical treatment with amoxicillin or amoxicillin/clavulanate were significantly associated with treatment failure, whereas first-line therapy with third-generation cephalosporins was associated with protection against negative outcomes. In conclusion, the increase in the resistance of uropathogens to commonly used antibiotics requires continuous monitoring, and recommendations for antibiotic choice need updating. In our epidemiological context, amoxicillin/clavulanate no longer seems to be the appropriate first-line therapy for children hospitalised for UTI, whereas third-generation cephalosporins continue to be
\end{abstract}


useful. To further limit the emergence of resistance, every effort to reduce and rationalise antibiotic consumption must be implemented.

Keywords: antibiotic therapy; antimicrobial resistance; extended-spectrum beta-lactamase-producing bacteria; extensively drug-resistant bacteria; multidrug resistance; urinary tract infection

\section{Introduction}

Urinary tract infections (UTIs) are among the most common infections in children. Indeed, it is estimated that $11.3 \%$ of females and $3.6 \%$ of males develop at least one episode of a UTI within the first 16 years of life [1]. The prevalence of UTIs has a bimodal trend, with a first peak within the first year of life and a second between two and four years of age, corresponding to toilet training [2]. Moreover, in the first 6 months of life, uncircumcised males have a 10-12 times greater risk of UTIs than females. However, after the first year of life, the relationship is reversed, with an increased risk for females that persists into adulthood [3]. Most paediatric UTIs are caused by Gram-negative microorganisms of the Enterobacteriaceae family, of which Escherichia coli is the most frequent, causing more than $70 \%$ of UTIs. Other frequent pathogens of the same family are Klebsiella spp., Enterobacter spp. and Proteus spp. Although Pseudomonas aeruginosa is a less frequent Gram-negative pathogen, it is often associated with more severe UTIs. Among rare cases of UTIs caused by Gram-positive microorganisms, those caused by Enterococcus spp. are most frequent $[4,5]$.

The development and spread of antibiotic resistance are increasingly important global public health problems, even in UTI, with variable prevalence in different geographical areas [6]. In recent years, the incidence of uropathogen resistance to commonly used antibiotics for paediatric UTI has increased worldwide. In the USA, out of 368,398 isolates in children with UTIs between January 1999 and December 2011, 1.97\% were identified as third-generation cephalosporin resistant, with an increase in all demographic and age groups [7]. In Turkey, comparing the data collected in a single paediatric institution from 2009 to 2014, it was shown that E. coli resistance during the study period increased for ampicillin from $47.1 \%$ to $89 \%$, for trimethoprim-sulphamethoxazole from $44.8 \%$ to $56 \%$ and for nitrofurantoin from $5.3 \%$ to $15.1 \%$ [8]. The most frequent risk factors associated with the development of UTIs due to antimicrobial-resistant pathogens are the previous use of antibiotics and urinary tract abnormalities [7-10]. Nevertheless, data for the surveillance of antibiotic resistance in UTIs frequently do not distinguish between adult and paediatric populations, and in many cases, the data are limited to single resistance mechanisms of specific pathogens, predominantly extended-spectrum beta-lactamase (ESBL)-producing E. coli. Furthermore, the prevalence of ESBL-producing pathogens in paediatric UTIs varies from $0.5 \%$ to $50 \%$ across studies [9-11]. In light of the variability in the data in the literature, it is necessary to conduct surveillance studies to determine the prevalence of antibiotic resistance in paediatric UTIs in specific geographical areas to optimize therapeutic management. Accordingly, this study aimed to describe the prevalence of antibiotic resistance among uropathogens in paediatric patients with UTI who were hospitalised in the last 8 years in the paediatric units of the Emilia-Romagna Region, Italy, as well as risk factors and outcomes associated with the onset of UTI caused by resistant pathogens.

\section{Methods}

\subsection{Study Design and Population}

In this observational, retrospective, multicentre study, medical records for paediatric patients of both sexes and under the age of 18 years who were hospitalised for UTI between 1 January 2012, and 30 June 2020, in the paediatric wards of Emilia-Romagna, Italy, were analysed. The medical records were extrapolated on the basis of the following diagnosisrelated group (DRG) codes and/or International Classification of Diseases 9th revision (ICD-9) diagnosis codes: DRG 322, infections of the kidney and urinary tract, age $<18$ years; 
ICD-9-CM 590.1, acute pyelonephritis; ICD-9-CM 590.3, cystic pyeloureteritis; ICD-9-CM 590.8, pyelonephritis, unspecified; ICD-9-CM 590.9: kidney infection, unspecified. Patients with congenital or acquired immunodeficiencies, undergoing immunosuppressive therapy, or with neoplastic diseases were excluded. Only patients with positive urine cultures as defined in the Italian Society of Paediatric Nephrology guidelines [11] and febrile UTI were included in the study. The study was approved by the Ethics Committee of the participating centres (AVEN Protocol number 904/2020/OSS/AOUPR), and the parents of the enrolled patients were contacted by phone by each centre to come and sign informed consent for study participation; patients aged $>8$ years signed informed assent.

\subsection{Data Evaluation}

All medical records of subjects under the age of 18 years who met the inclusion and exclusion criteria were retrospectively reviewed. The data collection was focused on demographic characteristics, remote and proximate pathological history, blood and urinary laboratory parameters at onset, radiological findings (i.e., kidney and urinary tract ultrasound, voiding cystoureterography, renal scintigraphy) and laboratory data following the acute episode, uroculture and antibiogram results, antibiotic therapies administered before admission, during hospitalisation and prescribed at discharge, trends in vital parameters and any procedures carried out.

Positive urocultures were defined as the identification of a single pathogenic species present at $\geq 10^{5} \mathrm{CFU} / \mathrm{mL}$. These cases were then analyzed by measuring frequency and describing the susceptibility/resistance of the individual pathogens. Pathogens that hydrolysed penicillin and first- to third-generation cephalosporins and aztreonam were defined phenotypically as ESBL [12]. Criteria for the definitions of multidrug resistance (MDR) and extensive drug resistance (XDR) were identified according to the combined guidelines of the Clinical and Laboratory Standards Institute (CLSI), the European Centre for Disease Prevention and Control (ECDC) and the Centers for Disease Control and Prevention (CDC) [12]. MDR pathogens were defined as non-susceptible to one agent in three antimicrobial categories. Pathogens were considered XDR if non-susceptible to one agent in all but two categories.

Risk factors as well as clinical, laboratory and renal ultrasound findings associated with UTI due to susceptible and resistant pathogens were investigated. All antibiotic molecules administered were recorded, and the clinical cure rate for therapies was evaluated in the entire study population using the clinical improvement of the patient with the resolution of fever and symptoms as a definition of therapeutic success.

For data collection, a special form was used for each patient. In the case of patients with multiple accesses within the inclusion criteria, the last access was chosen.

\subsection{Statistical Analysis}

Statistical analysis was conducted using R software v. 4.0.1. Descriptive statistics, as absolute and relative frequencies, means and standard deviations, were used to summarize the data. Pearson $\chi^{2}$ and Fisher's exact tests were used to assess differences on all categorical variables and compare the two periods of analysis (2012-2015 vs. 2016-2020). Considering the eight-year study periods, we compared the first four years of enrollment with the last four years of the study period. Independent samples $t$-tests and WilcoxonMann-Whitney tests were employed to compare the distribution of continuous variables. For all tests, an alpha $<0.05$ was considered statistically significant.

Univariable logistic regression models were then used to assess the effect of select risk factors and the onset of UTIs caused by resistant pathogens, as well as failure of empirical first-line treatment.

\section{Results}

Table 1 summarises the characteristics of the study population. Overall, 1801 children (mean age \pm standard deviation [SD], $1.9 \pm 3.5$ years) were enrolled during the study 
period, of whom 627 (34.8\%) were hospitalised in 2012-2015 and 1174 (65.2\%) in 20162020. Among them, 920 (51.1\%) were females, and 1297 (72.0\%) were of Caucasian origin. The children hospitalised during the years 2016-2020 were significantly older, were more frequently Caucasian and less often had a history of recurrent UTI in comparison with those hospitalised during the years 2012-2015.

Table 1. Demographic characteristics of the children with urinary tract infections (UTIs) according to years of hospitalisation.

\begin{tabular}{|c|c|c|c|}
\hline Characteristic & $\begin{array}{c}\text { Hospitalisation Period } \\
\begin{array}{c}2012-2015 \\
n=627\end{array}\end{array}$ & $\begin{array}{c}\text { Hospitalisation Period } \\
2016-2020 \\
n=1174\end{array}$ & $p$ Value \\
\hline Mean age (SD), years & $1.7(3.3)$ & $2.1(3.8)$ & 0.04 \\
\hline Sex, $n$. & & & 0.3 \\
\hline $\mathrm{F}$ & $296(47 \%)$ & $585(50 \%)$ & \\
\hline M & $331(53 \%)$ & $589(50 \%)$ & \\
\hline Ethnicity, $n$. & & & $<0.001$ \\
\hline Caucasian & $395(78 \%)$ & $902(83 \%)$ & \\
\hline Other & $11(2.2 \%)$ & $19(1.7 \%)$ & \\
\hline Prenatal pyelectasis, $n$. & $83(14 \%)$ & $141(12 \%)$ & 0.3 \\
\hline Prematurity at birth, $n$. & $54(9.0 \%)$ & $111(9.7 \%)$ & 0.6 \\
\hline Neonatal complications, $n$. & $64(11 \%)$ & $122(11 \%)$ & $>0.9$ \\
\hline Vescico-ureteral reflux, $n$. & $58(9.3 \%)$ & $86(7.3 \%)$ & 0.2 \\
\hline $\begin{array}{l}\text { Other urological } \\
\text { malformations, } n \text {. }\end{array}$ & $58(9.8 \%)$ & $95(8.4 \%)$ & 0.3 \\
\hline Urological surgery, $n$. & $17(2.8 \%)$ & $49(4.2 \%)$ & 0.13 \\
\hline History of recurrent $\mathrm{UTI}^{1}, n$. & $69(12 \%)$ & $98(8.6 \%)$ & 0.029 \\
\hline $\begin{array}{l}\text { Antibiotic therapy in the } 30 \\
\text { days before enrolment, } n \text {. }\end{array}$ & $72(12 \%)$ & $131(11 \%)$ & 0.7 \\
\hline
\end{tabular}

${ }^{1}$ Defined by at least 3 episodes in the preceding 6 months. SD: standard deviation.

Table 2 summarizes the most frequently detected pathogens according to the study period. E. coli (1361 cases, $75.6 \%)$ was the most frequently detected pathogen in both study periods, followed by K. pneumoniae (124 cases, 6.9\%) and P. aeruginosa (45 cases, 2.5\%). From 2012-2015 to 2016-2020, a significant increase in cases due to E. coli and a significant decrease in cases due to $P$. aeruginosa were observed.

Table 2. Aetiology of urinary tract infections according to years of hospitalisation.

\begin{tabular}{lccc}
\hline \multicolumn{1}{c}{ Pathogen } & $\begin{array}{c}\text { Hospitalisation } \\
\text { Period 2012-2015 } \\
\boldsymbol{n} \mathbf{= 6 2 7}\end{array}$ & $\begin{array}{c}\text { Hospitalisation } \\
\text { Period 2016-2020 } \\
\boldsymbol{n = 1 1 7 4}\end{array}$ & $\boldsymbol{p}$ Value \\
\hline Escherichia coli, $n$. & $453(\mathbf{7 2 . 0 \% )}$ & $908(77.0 \%)$ & 0.017 \\
Proteus mirabilis, $n$. & $9(1.4 \%)$ & $18(1.5 \%)$ & 0.9 \\
Klebsiella pneumoniae, $n$. & $49(7.8 \%)$ & $75(6.4 \%)$ & 0.3 \\
Pseudomonas aeruginosa, $n$. & $22(3.5 \%)$ & $23(2.0 \%)$ & 0.045 \\
Enterococcus faecalis, $n$. & $14(2.2 \%)$ & $21(1.8 \%)$ & 0.5 \\
Enterobacter spp., $n$. & $7(1.1 \%)$ & $16(1.4 \%)$ & 0.7 \\
Citrobacter koseri, $n$. & $5(0.8 \%)$ & $8(0.7 \%)$ & 0.8 \\
Staphylococcus aureus, $n$. & $1(0.2 \%)$ & $4(0.3 \%)$ & 0.7 \\
Group B Streptococcus, $n$. & $2(0.3 \%)$ & $1(<0.1 \%)$ & 0.3 \\
Other, $n$. & $10(1.7 \%)$ & $13(1.2 \%)$ & 0.4 \\
Missing, $n$. & $55(8.8 \%)$ & $87(7.4 \%)$ & 0.6 \\
\hline
\end{tabular}

Table 3 summarises antibiotic susceptibility according to years of hospitalisation. Overall, $840 / 1801$ cases $(46.7 \%)$ were due to antimicrobial-resistant uropathogens: $83(4.7 \%)$ to ESBL, $119(6.7 \%)$ to MDR and $4(0.2 \%)$ to XDR bacteria. Amoxicillin resistance was observed in $840(46.7 \%)$ cases, amoxicillin/clavulanate resistance in $610(33.8 \%)$, trimethoprimsulfametoxazole resistance in $391(21.7 \%)$, third-generation cephalosporin resistance in 
$210(11.8 \%)$, aminoglicosyde resistance in $66(3.7 \%)$ and fluoroquinolone resistance in $4(0.2 \%)$. Antimicrobial resistance increased significantly from 2012-2015 to 2016-2020 $(41.9 \%$ vs. $49.1 \% ; p<0.001)$, though the prevalence of MDR uropathogens decreased. The most frequent ESBL pathogens were E. coli (62/83, 74.7\%) and K. pneumoniae (10/83, 12.0\%), and the most frequent MDR pathogens were E. coli $(68 / 119,57.1 \%)$, P. aeruginosa $(12 / 119$, $10.1 \%)$, K. pneumoniae $(7 / 119,5.9 \%)$ and Proteus mirabilis $(6 / 119,5.0 \%)$. XDR pathogens were E. coli (3/4) and K. pneumoniae (1/4).

Table 3. Antibiotic susceptibility among uropathogens isolated from children hospitalised for urinary tract infection according to years of hospitalisation.

\begin{tabular}{cccc}
\hline Characteristic & $\begin{array}{c}\text { Hospitalisation } \\
\text { Period 2012-2015 } \\
\boldsymbol{n} \mathbf{= 6 2 7}\end{array}$ & $\begin{array}{c}\text { Hospitalisation } \\
\text { Period 2016-2020 } \\
\boldsymbol{n = 1 1 7 4}\end{array}$ & $\boldsymbol{p}$ Value \\
\hline Antimicrobial susceptibility & $364(58.1 \%)$ & $597(50.9 \%)$ & $<0.001$ \\
Antimicrobial resistance other & $180(28.7 \%)$ & $454(38.7 \%)$ & $<0.001$ \\
than ESBL, MDR, XDR & $26(4.1 \%)$ & $57(4.9 \%)$ & 0.7 \\
ESBL & $56(8.9 \%)$ & $63(5.4 \%)$ & 0.001 \\
MDR & $1(0.2 \%)$ & $3(0.3 \%)$ & $>0.9$ \\
XDR &
\end{tabular}

ESBL: extended-spectrum beta-lactamase; MDR: multidrug resistant; XDR: extensively drug resistant.

Table 4 summarises the results of univariate analysis for the risk of being infected by resistant pathogens, ESBL or MDR/XDR uropathogens. A history of recurrent UTI, antibiotic prophylaxis and antibiotic therapy in the preceding 30 days were significantly associated with an increased risk of UTI due to antimicrobial-resistant, ESBL or XDR/MDR pathogens, whereas urological malformations were significantly associated with a risk of antimicrobial resistance other than ESBL, MDR and XDR as well as with XDR/MDR UTI.

Table 4. Risk factors associated with antibiotic resistance among children hospitalised for urinary tract infection.

\begin{tabular}{|c|c|c|c|c|c|c|c|c|c|}
\hline \multirow[b]{2}{*}{ Characteristic } & \multicolumn{3}{|c|}{$\begin{array}{c}\text { Antimicrobial Resistance other } \\
\text { than ESBL, MDR, XDR } \\
n=634\end{array}$} & \multicolumn{3}{|c|}{$\begin{array}{l}\text { ESBL } \\
n=83\end{array}$} & \multicolumn{3}{|c|}{$\begin{array}{c}\text { MDR/XDR } \\
n=123\end{array}$} \\
\hline & OR & $95 \%$ CI & $p$ Value & OR & $95 \% \mathrm{CI}$ & $p$ Value & OR & $95 \% \mathrm{CI}$ & $p$ Value \\
\hline Age & 1.03 & $0.98,1.08$ & 0.18 & 1.02 & $0.96,1.08$ & 0.45 & 1.03 & $0.98,1.08$ & 0.18 \\
\hline \multicolumn{10}{|l|}{ Sex } \\
\hline $\mathrm{F}$ & & & & - & - & & - & - & \\
\hline M & 1.16 & $0.80,1.69$ & 0.42 & 1.1 & $0.70,1.71$ & 0.68 & 1.16 & $0.80,1.69$ & 0.42 \\
\hline Recurrent UTI & 4.31 & $2.70,6.75$ & $<0.001$ & 2.57 & $1.40,4.47$ & 0.001 & 4.31 & $2.70,6.75$ & $<0.001$ \\
\hline $\begin{array}{l}\text { Antibiotic } \\
\text { prophylaxis }\end{array}$ & 5.34 & $2.74,10.2$ & $<0.001$ & 2.65 & $1.18,5.55$ & 0.013 & 5.34 & $2.74,10.2$ & $<0.001$ \\
\hline $\begin{array}{l}\text { Antibiotic } \\
\text { therapy in the } \\
\text { preceding } \\
30 \text { days }\end{array}$ & 2.83 & $1.76,4.44$ & $<0.001$ & 2.08 & $1.13,3.60$ & 0.013 & 2.83 & $1.76,4.44$ & $<0.001$ \\
\hline $\begin{array}{l}\text { Vescico-ureteral } \\
\text { reflux } n\end{array}$ & 1.10 & $0.76,1.63$ & 0.63 & & & & & & \\
\hline $\begin{array}{l}\text { Other urological } \\
\text { malformations }\end{array}$ & 2.67 & $1.71,4.09$ & $<0.001$ & 1.18 & $0.61,2.10$ & 0.6 & 2.67 & $1.71,4.09$ & $<0.001$ \\
\hline Nephromegaly & 1.14 & $0.39,2.66$ & 0.78 & 0.95 & $0.23,2.64$ & 0.93 & 1.14 & $0.39,2.66$ & 0.78 \\
\hline Pyelectasis & 1.19 & $0.79,1.77$ & 0.41 & 0.93 & $0.57,1.50$ & 0.76 & 1.19 & $0.79,1.77$ & 0.41 \\
\hline
\end{tabular}

$\mathrm{CI}$, confidence interval; ESBL, extended-spectrum beta-lactamase; MDR, multidrug resistant; OR, odds ratio; XDR, extensively drug resistant.

No significant differences in clinical findings, blood exams or urinary exams between the groups were observed. The empirical therapy administered to the study population is provided in Table 5. Third-generation cephalosporins were the most frequently prescribed antibiotics during the whole study period, and a significant increase in the prescription of 
amoxicillin/clavulanate during the years 2016-2020 in comparison with the years 20122015 was observed.

Table 5. Empirical therapy administered to the study population.

\begin{tabular}{cccc}
\hline Therapy & $\begin{array}{c}\text { Hospitalisation } \\
\text { Period 2012-2015 } \\
\boldsymbol{n = 6 2 7}\end{array}$ & $\begin{array}{c}\text { Hospitalisation } \\
\text { Period 2016-2020 } \\
\boldsymbol{n = 1 1 7 4}\end{array}$ & $\boldsymbol{p}$ Value \\
\hline Amoxicillin & $14(2.2 \%)$ & $20(1.7 \%)$ & 0.4 \\
Amoxicillin/clavulanate & $130(21 \%)$ & $363(31 \%)$ & $<0.001$ \\
Ampicillin +.aminoglycosides & $112(18 \%)$ & $185(16 \%)$ & 0.3 \\
third-generation & $284(45 \%)$ & $479(41 \%)$ & 0.066 \\
cephalosporins & & & \\
third-generation & $29(4.6 \%)$ & $60(5.1 \%)$ & 0.7 \\
cephalosporins + & $12(1.9 \%)$ & $15(1.3 \%)$ & 0.3 \\
aminoglycosides & $1(0.2 \%)$ & $2(0.2 \%)$ & $>0.9$ \\
Aminoglycosides & $2(0.3 \%)$ & $0(0 \%)$ & 0.12 \\
Quinolones & $17(2.7 \%)$ & $30(2.6 \%)$ & 0.8 \\
TMX-SMZ & & & \\
Other therapies & & & \\
\hline
\end{tabular}

TMX-SMZ: trimethoprim/sulfamethoxazole.

Overall, empirical antibiotic therapy failed in 172 children (9.6\%). Table 6 shows factors significantly associated with treatment failure. Having ESBL or MDR/XDR uropathogens, history of recurrent UTI, antibiotic therapy in the preceding 30 days, having pielectasis or nephromegaly at echography, and empirical treatment with amoxicillin or amoxicillin/clavulanate were significantly associated with treatment failure. Conversely, empirical first-line treatment with third-generation cephalosporins was associated with protection against a negative outcome. In the presence of ESBL and MDR/XDR strains, third-generation cephalosporins alone were always associated with treatment failure.

Table 6. Factors significantly associated with treatment failure.

\begin{tabular}{cccc}
\hline Characteristic & OR & $\mathbf{9 5 \%}$ CI & $p$ Value \\
\hline Antimicrobial resistance other than ESBL, & 1.39 & $1.00,1.93$ & 0.051 \\
MDR/XDR & 3.69 & $2.12-6.21$ & $<0.001$ \\
ESBL pathogens & 4.07 & $2.57,6.36$ & $<0.001$ \\
MDR/XDR pathogens & 1.03 & $0.98,1.07$ & 0.21 \\
Age & 1.08 & $0.78,1.48$ & 0.65 \\
Male sex & 2.04 & $1.28,3.16$ & 0.002 \\
Antibiotic prophylaxis & 1.87 & $0.93,3.56$ & 0.064 \\
Vescico-ureteral reflux & 1.75 & $1.12,2.66$ & 0.011 \\
Pielectasis & 1.17 & $0.79,1.80$ & 0.45 \\
Nephribiotic therapy in the previous 30 days & 1.49 & $0.98,2.22$ & 0.055 \\
Other urological malformations & 1.41 & $1.01,1.96$ & 0.045 \\
Treatment with amoxicillin & 2.85 & $1.01,1.96$ & $<0.001$ \\
Treatment with amoxicillin/clavulanate & 5.06 & $2.38,10.2$ & $<0.001$ \\
Treatment with ampicillin + aminoglycosides & 1.67 & $1.20,2.32$ & 0.002 \\
Treatment with third-generation cephalosporins & 0.99 & $0.64,1.49$ & 0.96 \\
Treatment with third-generation cephalosporins + & 0.46 & $0.32,0.65$ & $<0.001$ \\
aminoglycosides & 0.77 & $0.32,1.57$ & 0.51 \\
Treatment with aminoglycosides & 1.20 & $0.28,3.50$ & 0.77
\end{tabular}

CI: confidence interval; ESBL: extended-spectrum beta-lactamase MDR: multidrug resistant; OR, odds ratio; XDR: extensively drug resistant.

\section{Discussion}

This study shows that antimicrobial resistance among uropathogens is an increasing phenomenon in children hospitalised for UTI in Italy, with a remarkable prevalence of ESBL 
as well as MDR/XDR strains. In general, previous antibiotic administration, including for UTI prophylaxis, is associated with resistance to antibiotics. Interestingly, risk factors for empirical treatment failure included having ESBL or MDR/XDR uropathogens, history of recurrent UTI, antibiotic therapy in the preceding 30 days, and empirical treatment with amoxicillin or amoxicillin/clavulanate, whereas empirical treatment with third-generation cephalosporins was associated with protection against poor outcomes.

Awareness of upper UTI aetiology and variation in pathogen susceptibility to antibiotics is essential for the choice of an effective therapy. As previously reported, our study showed E. coli and K. pneumoniae to be the most frequent uropathogens in children hospitalised for UTI and those most commonly observed in cases involving resistance [13-16]. In our population, resistance to amoxicillin and amoxicillin clavulanate was high, whereas resistance to third-generation cephalosporins was detected in $<10 \%$ of uropathogens, in line with findings described by other authors [16-18]. The prevalence of ESBL, MDR and XDR uropathogens $(4.7 \%, 6.7 \%$ and $0.2 \%$, respectively) was similar to that previously reported in Europe and the United States [18-20] and lower than that reported in Asian countries [21-23]. However, it is not possible to draw conclusions on the absence of increase in ESBL and XDR strains as well as in the decrease of MDR strains during the study period.

To assure the highest probability of bacterial eradication, official guidelines indicate which antibiotics must be used. Taking into account the increase in the incidence of ESBL cases, Italian guidelines were recently updated, and an amoxicillin/clavulanic acid combination was indicated as the drug of choice for paediatric UTI treatment, highlighting that first- to third-generation cephalosporins have no additional role in this regard, as they are, in many cases, ineffective against ESBL-producing strains [10]. This explains why our data showed a significant increase in the prescription of amoxicillin/clavulanate during the study period. In contrast, although updated in 2016 [24], the American Academic of Pediatrics guidelines did not change previous recommendations that included 1st- and third-generation cephalosporins as potentially effective for the treatment of paediatric first UTI [25]. Similar limitations seem to be present in the NICE guidelines that, despite being updated in 2018, still indicate cefalexin as a first-line drug and recommend the use of amoxicillin/clavulanic acid only when culture results are available and the pathogen is found to be susceptible to the combination [26]. Interestingly, in our study, empirical treatment with penicillins and beta-lactamase-resistant penicillins was associated with treatment failure, whereas the use of third-generation cephalosporins as empirical first-line therapy was associated with protection against poor outcomes, with important implications for clinical practice in Italy. These results suggest that the use of amoxicillin/clavulanate as first-line empirical therapy in children hospitalised for UTI should be carefully re-evaluated but that third-generation cephalosporins appear to remain a valid first-line therapeutic option. The use of aminoglycosides should be recommended in the case of ESBL pathogens, though carbapenems should be limited to MDR and XDR strains [27].

Proper identification of patients at increased risk of antibiotic resistance can reduce the risk of ineffective therapy. In our study population, the previous use of antibiotics was the most important risk factor associated with antibiotic resistance. Antibiotics are among the drugs most commonly prescribed to children in hospital and community settings [28,29]. Unfortunately, a great number of these antibiotic prescriptions are unnecessary or inappropriate, as shown by the evidence that these drugs are frequently given to children who do not have bacterial diseases or an infectious disease [30,31]. The high prevalence of amoxicillin-clavulanate resistance can be explained by the reported high prescription rate of this drug in children with common respiratory infections (i.e., pharyngotonsillitis and acute otitis media) in the Emilia-Romagna Region [32] and highlights the importance of antimicrobial stewardship projects for a more rational use of this drug $[33,34]$. Regarding UTIs, one of the most common causes of microbial selection and emergence of resistance is the administration of antibiotics for prophylaxis in children with recurrent UTI episodes, especially when a structural or functional abnormality of the urinary tract is diagnosed [35]. In most cases, prophylaxis is not proven to be beneficial for preventing new renal scarring 
in children and is no longer recommended in official guidelines [36]. Despite this lack of recommendation, it is still implemented in many cases and amoxicillin-clavulanate is the most frequently prescribed antibiotic for this purpose [10], promoting the emergence of resistance and the development of difficult-to-treat new UTI episodes [37].

Nevertheless, a number of studies suggest that resistant UTI can occur even in children without any risk factors [38]. Although the presence of resistant uropathogens is associated with poor outcomes and the risk of complications, in routine practice, the risk of serious immediate or long-term clinical problems due to discordant therapy is lower than expected $[39,40]$. Despite some exceptions, studies evaluating outcomes of paediatric UTIs according to the antibiotic therapy administered have shown that in a relevant number of cases, the outcome of children receiving drugs that are ineffective against the infectious pathogen in vitro did not differ from children given concordant therapy [41]. At least two factors might explain why febrile UTIs can be cured even in the absence of effective in vitro antibiotic therapy. A certain number of febrile UTIs can resolve spontaneously, as was demonstrated for other bacterial diseases [42]. Second, it cannot be excluded that the administered antibiotic can reach urine and renal parenchyma concentrations much higher than those in blood after usual doses and that are used to define resistance in vitro [43,44]. In both, it seems likely that, eradication of the pathogens at the site of infection can occur despite discordant therapy, at least in some cases.

Limitations of the study included its retrospective nature, the different number of patients evaluated in the two study periods and the fact that the research is limited to a definite epidemiologic context. However, the strict inclusion criteria and the long duration of the study period permit to draw important results on what happens in real life.

\section{Conclusions}

Despite being very common and well-studied, UTIs in paediatric patients remain challenging and this manuscript improves clinical knowledge on their management. We highlighted that the increase in resistance of uropathogens to commonly used antibiotics requires continuous monitoring of microbiological characteristics of UTIs and updating of recommendations for antibiotic choice. In our epidemiological context, amoxicillin/clavulanate no longer seems to be the appropriate first-line therapy for children hospitalised for UTI, whereas third-generation cephalosporins continue to be helpful. In order to selectively use cephalosporins so as to avoid increasing resistance to this class of antibiotics, in future studies using multivariate analysis it may be interesting to understand if a differentiated approach can be adopted using amoxicillin-clavulanate at the first UTI and cephalosporins in the presence of second and subsequent infections. The emergence of antibiotic resistance is an unavoidable phenomenon closely correlating with the use of antibiotics themselves. To limit the emergence of resistance, every effort to reduce and rationalise antibiotic consumption must be made. Increased use of antibiotic stewardship can be greatly effective in this regard.

Author Contributions: S.E. designed the study, supervised the project, participated in patients' enrollment and wrote the first draft of the manuscript; G.M. and C.C. performed the statistical analysis; M.D.C., M.C., G.V., C.L.S., C.M., A.F., A.I., A.C., L.I., M.L.C., L.P., C.G. and G.B. participated in patients' enrollment and gave a substantial contribution. All authors have read and agreed to the published version of the manuscript.

Funding: This research received no external funding.

Institutional Review Board Statement: The study was conducted according to the guidelines of the Declaration of Helsinki, and approved by the Ethics Committee of the participating Centers (Emilia-Romagna Area Vasta Nord, Area Vasta Centro and Area Vasta Sud).

Informed Consent Statement: Informed consent was obtained from all the parents of the enrolled patients; patients aged $>8$ years signed informed consent.

Data Availability Statement: The data presented in this study are available in this article. 
Acknowledgments: We would like to thank the other members of the UTI-Ped-ER Study Group: Alberto Argentiero, Giovanni Autore, Luca Bernardi, Giulia Dal Canto, Cosimo Neglia, Paediatric Clinic, University Hospital, Department of Medicine and Surgery, University of Parma, Parma, Italy; Ivana Cortina, Maria Elena Capra, Paediatrics and Neonatology Unit, Guglielmo da Saliceto Hospital, Piacenza, Italy; Consuelo Benincasa, Agnese Addeo, Rosa Elisa Saia, Francesca Lelli, Paediatrics Unit, AUSL Romagna, Rimini, Italy; Andrea Pession, Andrea Pasini, Francesco Baccelli, Laura Bruni, Giulia Gallotta, Adelaide Corvaglia, Paediatric Unit, IRCCS Azienda Ospedaliero-Universitaria di Bologna, Bologna, Italy; Marcello Lanari, Paediatric Emergency Unit, IRCCS Azienda OspedalieroUniversitaria di Bologna, Bologna, Italy; Agnese Suppiej, Claudia Cafolla, Federica Boselli, Paediatric Clinic, University of Ferrara, Ferrara, Italy; Enrico Valletta, Vittorio Venturoli, Paediatric Unit, Forlì Hospital, AUSL Romagna, Forlì, Italy; Luca Casadio, Ilaria Polenzani, Federico Marchetti, Paediatrics and Neonatology Unit, Ravenna Hospital, AUSL Romagna, Ravenna, Italy; Alessandro De Fanti, Paediatrics Unit, Santa Maria Nuova Hospital, AUSL-IRCCS of Reggio Emilia, Reggio Emilia, Italy.

Conflicts of Interest: The authors declare no conflict of interest.

\section{References}

1. Stephens, G.M.; Akers, S.; Nguyen, H.; Woxland, H. Evaluation and management of urinary tract infections in the school-aged child. Prim. Care 2015, 42, 33-41. [CrossRef] [PubMed]

2. Korbel, L.; Howell, M.; Spencer, J.D. The clinical diagnosis and management of urinary tract infections in children and adolescents. Paediatr. Int. Child Health 2017, 37, 273-279. [CrossRef]

3. Balighian, E.; Burke, M. Urinary Tract Infections in Children. Pediatr. Rev. 2018, 39, 3-12. [CrossRef]

4. Edlin, R.S.; Shapiro, D.J.; Hersh, A.L.; Copp, H.L. Antibiotic resistance patterns of outpatient pediatric urinary tract infections. J. Urol. 2013, 190, 222-227. [CrossRef]

5. Khoshnood, S.; Heidary, M.; Mirnejad, R.; Bahramian, A.; Sedighi, M.; Mirzaei, H. Drug-resistant gram-negative uropathogens: A review. Biomed Pharmacother. 2017, 94, 982-994. [CrossRef]

6. Raman, G.; McMullan, B.; Taylor, P.; Mallitt, K.A.; Kennedy SEMultiresistant, E. coli urine infections in children: A case-control study. Arch. Dis. Child 2018, 103, 336-340. [CrossRef] [PubMed]

7. Logan, L.K.; Braykov, N.P.; Weinstein, R.A.; Laxminarayan, R.; CDC Epicenters Prevention Program. Extended-Spectrum $\beta$-Lactamase-Producing and Third-Generation Cephalosporin-Resistant Enterobacteriaceae in Children: Trends in the United States, 1999-2011. J. Pediatric. Infect. Dis. Soc. 2014, 3, 320-328. [CrossRef]

8. Erol, B.; Culpan, M.; Caskurlu, H.; Sari, U.; Cag, Y.; Vahaboglu, H.; Özumut, S.H.; Karaman, M.I.; Caskurlu, T. Changes in antimicrobial resistance and demographics of UTIs in pediatric patients in a single institution over a 6-year period. J. Pediatr. Urol. 2018, 14, 176.e1-176.e5. [CrossRef] [PubMed]

9. Mahony, M.; McMullan, B.; Brown, J.; Kennedy, S.E. Multidrug-resistant organisms in urinary tract infections in children. Pediatr. Nephrol. 2019, 35, 1563-1573. [CrossRef] [PubMed]

10. Perez Heras, I.; Sanchez-Gomez, J.C.; Beneyto-Martin, P.; Ruano-de-Pablo, L.; Losada-Pinedo, B. Community-onset extendedspectrum beta-lactamase producing Escherichia coli in urinary tract infections in children from 2015 to 2016: Prevalence, risk factors, and resistances. Medicine 2017, 96, e8571. [CrossRef]

11. Ammenti, A.; Alberici, I.; Brugnara, M.; Chimenz, R.; Guarino, S.; La Manna, A.; La Scola, C.; Maringhini, S.; Maringhini, S.; Materassi, M.; et al. Italian Society of Pediatric Nephrology. Updated Italian recommendations for the diagnosis, treatment and follow-up of the first febrile urinary tract infection in young children. Acta Paediatr. 2020, 109, 236-247. [CrossRef] [PubMed]

12. Magiorakos, A.P.; Srinivasan, A.; Carey, R.B.; Carmeli, Y.; Falagas, M.E.; Giske, C.G.; Harbarth, S.; Hindler, J.F.; Kahlmeter, G.; Olsson-Liljequist, B.; et al. Multidrug-Resistant, Extensively Drug-Resistant and Pandrug-Resistant Bacteria: An International Expert Proposal for Interim Standard Definitions for Acquired Resistance. Clin. Microbiol. Infect. 2012, 18, 268-281. [CrossRef] [PubMed]

13. Koçak, M.; Büyükkaragöz, B.; Çelebi Tayfur, A.; Çaltik, A.; Köksoy, A.Y.; Çizmeci, Z.; Günbey, S. Causative pathogens and antibiotic resistance in children hospitalized for urinary tract infection. Pediatr. Int. 2016, 58, 467-471. [CrossRef] [PubMed]

14. Belete, Y.; Asrat, D.; Woldeamanuel, Y.; Yihenew, G.; Gize, A. Bacterial Profile And Antibiotic Susceptibility Pattern Of Urinary Tract Infection Among Children Attending Felege Hiwot Referral Hospital, Bahir Dar, Northwest Ethiopia. Infect. Drug Resist. 2019, 12, 3575-3583. [CrossRef]

15. Vazouras, K.; Velali, K.; Tassiou, I.; Anastasiou-Katsiardani, A.; Athanasopoulou, K.; Barbouni, A.; Jackson, C.; Folgori, L.; Zaoutis, T.; Basmaci, R.; et al. Antibiotic treatment and antimicrobial resistance in children with urinary tract infections. J. Glob. Antimicrob. Resist. 2020, 20, 4-10. [CrossRef]

16. Montagnani, C.; Tersigni, C.; D’Arienzo, S.; Miftode, A.; Venturini, E.; Bortone, B.; Bianchi, L.; Chiappini, E.; Forni, S.; Gemmi, F.; et al. Resistance Patterns from Urine Cultures in Children Aged 0 to 6 Years: Implications for Empirical Antibiotic Choice. Infect. Drug Resist. 2021, 14, 2341-2348. [CrossRef]

17. Wragg, R.; Harris, A.; Patel, M.; Robb, A.; Chandran, H.; McCarthy, L. Extended spectrum beta lactamase (ESBL) producing bacteria urinary tract infections and complex pediatric urology. J. Pediatr. Surg. 2017, 52, 286-288. [CrossRef] [PubMed] 
18. Pierantoni, L.; Andreozzi, L.; Ambretti, S.; Dondi, A.; Biagi, C.; Baccelli, F.; Lanari, M. Three-Year Trend in Escherichia coli Antimicrobial Resistance among Children's Urine Cultures in an Italian Metropolitan Area. Children 2021, 8, 597.

19. Degnan, L.A.; Milstone, A.M.; Diener-West, M.; Lee, C.K. Extended-Spectrum Beta-Lactamase Bacteria from Urine Isolates in Children. J. Pediatr. Pharmacol. Ther. 2015, 20, 373-377. [CrossRef]

20. Zerr, D.M.; Miles-Jay, A.; Kronman, M.P.; Zhou, C.; Adler, A.L.; Haaland, W.; Weissman, S.J.; Elward, A.; Newland, J.G.; Zaoutis, T.; et al. Previous Antibiotic Exposure Increases Risk of Infection with Extended-Spectrum- $\beta$-Lactamase- and AmpCProducing Escherichia coli and Klebsiella pneumoniae in Pediatric Patients. Antimicrob. Agents Chemother. 2016, 60, 4237-4243. [CrossRef]

21. Shettigar, S.C.G.; Roche, R.; Nayak, N.; Anitha, K.B.; Soans, S. Bacteriological profile, antibiotic sensitivity pattern, and detection of extended-spectrum $\beta$-lactamase in the isolates of urinary tract infection from children. J. Child Health 2016, 3, 5. [CrossRef]

22. Moore, C.E.; Sona, S.; Poda, S.; Putchhat, H.; Kumar, V.; Sopheary, S.; Stoesser, N.; Bousfield, R.; Day, N.; Parry, C.M. Antimicrobial susceptibility of uropathogens isolated from Cambodian children. Paediatr. Int. Child Health 2016, 36, 113-117. [CrossRef]

23. Topaloglu, R.; Er, I.; Dogan, B.G.; Bilginer, Y.; Ozaltin, F.; Besbas, N.; Ozen, S.; Bakkaloglu, A.; Gur, D. Risk factors in communityacquired urinary tract infections caused by ESBL-producing bacteria in children. Pediatr. Nephrol. 2010, 25, 919-925. [CrossRef] [PubMed]

24. American Academy of Pediatrics. Reaffirmation of AAP Clinical Practice Guideline: The Diagnosis and Management of the Initial Urinary Tract Infection in Febrile Infants and Young Children 2-24 Months of Age. Pediatrics 2016, 138, e20163026. [CrossRef] [PubMed]

25. American Academy of Pediatrics. Subcommittee on Urinary Tract Infection, Steering Committee on Quality Improvement and Management Urinary Tract Infection: Clinical Practice Guideline for the Diagnosis and Management of the Initial UTI in Febrile Infants and Children 2 to 24 Months. Pediatrics 2011, 128, 595-610. [CrossRef]

26. National Institute for Health and Care Excellence. Urinary Tract Infection in under 16s: Diagnosis and Management. Available online: https:/ / www.nice.org.uk/guidance/cg54 (accessed on 2 January 2021).

27. Poirel, L.; Kieffer, N.; Nordmann, P. In vitro evaluation of dual carbapenem combinations against carbapenemase-producing Enterobacteriaceae. J. Antimicrob. Chemother. 2016, 71, 156-161. [CrossRef] [PubMed]

28. Gerber, J.S.; Newland, J.G.; Coffin, S.E.; Hall, M.; Thurm, C.; Prasad, P.A.; Feudtner, C.; Zaoutis, T.E. Variability in antibiotic use at children's hospitals. Pediatrics 2010, 126, 1067-1073. [CrossRef] [PubMed]

29. Fanelli, U.; Chiné, V.; Pappalardo, M.; Gismondi, P.; Esposito, S. Improving the Quality of Hospital Antibiotic Use: Impact on Multidrug-Resistant Bacterial Infections in Children. Front. Pharmacol. 2020, 11, 745. [CrossRef]

30. Principi, N.; Esposito, S. Unsolved problems and new medical approaches to otitis media. Expert Opin. Biol. Ther. 2020, 20, 741-749. [CrossRef]

31. Principi, N.; Esposito, S. Antimicrobial stewardship in paediatrics. BMC Infect Dis. 2016, 16, 424. [CrossRef]

32. Moro, M.L.; Marchi, M.; Gagliotti, C.; Di Mario, S.; Resi, D. “Progetto Bambini a Antibiotici [ProBA]” Regional Group. Why do paediatricians prescribe antibiotics? Results of an Italian regional project. BMC Pediatr. 2009, 9, 69. [CrossRef] [PubMed]

33. Fanelli, U.; Pappalardo, M.; Chinè, V.; Gismondi, P.; Neglia, C.; Argentiero, A.; Calderaro, A.; Prati, A.; Esposito, S. Role of Artificial Intelligence in Fighting Antimicrobial Resistance in Pediatrics. Antibiotics 2020, 9, 767. [CrossRef] [PubMed]

34. Di Mario, S.; Gagliotti, C.; Buttazzi, R.; Cisbani, L.; Di Girolamo, C.; Brambilla, A.; Moro, M.L.; Regional Working Group. Progetto ProBA-Progetto Bambini e Antibiotici-2014. Observational pre-post study showed that a quality improvement project reduced paediatric antibiotic prescribing rates in primary care. Acta Paediatr. 2018, 107, 1805-1809. [CrossRef]

35. Montini, G.; Hewitt, I. Urinary tract infections: To prophylaxis or not to prophylaxis? Pediatr. Nephrol. 2009, $24,1605-1609$. [CrossRef]

36. Meena, J.; Thomas, C.C.; Kumar, J.; Raut, S.; Hari, P. Non-antibiotic interventions for prevention of urinary tract infections in children: A systematic review and meta-analysis of randomized controlled trials. Eur. J. Pediatr. 2021. [CrossRef] [PubMed]

37. Alsubaie, S.S.; Barry, M.A. Current status of long-term antibiotic prophylaxis for urinary tract infections in children: An antibiotic stewardship challenge. Kidney Res. Clin. Pract. 2019, 38, 441-454. [CrossRef]

38. Kim, Y.H.; Yang, E.M.; Kim, C.J. Urinary tract infection caused by community-acquired extended-spectrum beta-lactamase producing bacteria in infants. J. Pediatr. 2017, 93, 260-266. [CrossRef]

39. Shaikh, N.; Ewing, A.L.; Bhatnagar, S.; Hoberman, A. Risk of renal scarring in children with a first urinary tract infection: A systematicreview. Pediatrics 2010, 126, 1084-1091. [CrossRef]

40. Wang, M.E.; Lee, V.; Greenhow, T.L.; Beck, J.; Bendel-Stenzel, M.; Hames, N.; McDaniel, C.E.; King, E.E.; Sherry, W.; Parmar, D.; et al. Clinical Response to Discordant Therapy in Third-Generation Cephalosporin-Resistant UTIs. Pediatrics 2020, 145, e20191608. [CrossRef]

41. Newman, T.B.; Bernzweig, J.A.; Takayama, J.I.; Finch, S.A.; Wasserman, R.C.; Pantell, R.H. Urine Testing and Urinary Tract Infections in Febrile Infants Seen in Office Settings: The Pediatric Research in Office Settings' Febrile Infant Study. Arch. Pediatr. Adolesc. Med. 2002, 156, 44-54. [CrossRef]

42. Esposito, S.; Marchisio, P.; Tenconi, R.; Principi, N. Antibiotic treatment of acute otitis media in pediatrics. Future Microbiol. 2011, 6, 485-488. [CrossRef] [PubMed]

43. Frimodt-Møller, N. Correlation between pharmacokinetic/pharmacodynamic parameters and efficacy for antibiotics in the treatment of urinary tract infection. Int. J. Antimicrob. Agents 2002, 19, 546-553. [CrossRef] 
44. Edson, R.S.; Terrell, C.L. The aminoglycosides. Mayo Clin. Proc. 1999, 74, 519-528. [CrossRef] 